\title{
Creating teacher capacity in Early Childhood Education and Care institutions implementing an authoritative adult style
}

\author{
Heidi Omdal ${ }^{1}$
}

Published online: 29 December 2017

(C) The Author(s) 2017. This article is an open access publication

\begin{abstract}
The being together intervention intends to raise teacher capacity in Norwegian Early Childhood Education and Care (ECEC) institutions and promote social and emotional development in preschoolers by implementing an authoritative (warm and predictable) adult style in the institution. An authoritative adult balances between building up high quality interactions with children, while at the same time having a predictable structure with clear norms and social expectations in the learning environment. The purpose of this study was to investigate what helped the ECEC institutions to successfully implement the program principles and core components, and what were the challenges. The staff groups of seven Norwegian ECEC institutions in different municipalities who took part in the innovation were interviewed at the beginning and before the end of the first year of implementation. Data analysis identified five success criteria in the implementation process; strong commitment to the authoritative adult style, strong focus on the implementation process, advanced support systems, highly involved leaders, and a collective orientation. These elements resulted in a shared vision and an academically grounded practice in the ECEC institutions. Staff members without formal professional training and a lack of written documentation in the ECEC institutions should be given more consideration in further improvement of the capacity building.
\end{abstract}

Keywords Authoritative adult style - Capacity building - Collective orientation · Early intervention · Early Childhood Education and Care · Implementation $\cdot$ Social interactions

Heidi Omdal

heidi.omdal@uia.no

1 Department of Education, University of Agder, Ingridsvei 4 B, 4633 Kristiansand, Norway 


\section{Introduction}

Early Childhood Education and Care (ECEC) is one of the best investments a country can make to promote lifelong learning opportunities for all and prevent later remedial interventions (UNESCO 2015). Standards for the ECEC system are essential to provide guidance and continuity so that all young children and their families are guaranteed a minimum level of quality (The World Bank 2013). There are common organizational (e.g. initial education, training, mentoring/supervision, parent involvement, curriculum), structural (e.g. adult-child ratios, group size, physical environment and availability of equipment and pedagogical materials) and process (e.g. caregiver-child and child-child interactions) elements of quality that predict child development outcomes including their physical, cognitive, linguistic and socioemotional development (The World Bank 2013). Research evidence suggests that highly qualified staff may have a positive influence on educational quality (Elliot 2006; Siraj-Blatchford et al. 2002). It is assumed that ECEC teachers need several professional competencies and skills to offer high-quality learning environments for young children so that they can reach their full potential (OECD 2015). International research evidence shows that a child-oriented conception of ECEC may lead to better outcomes regarding socioemotional development, interests and motivation (Ministry of Education and Research 2015).

ECEC institutions are understood as learning organizations in constant change. Many researchers agree that teachers' educational beliefs, such as their epistemological beliefs, their definition of their professional role, values, attitudes and learning goals are crucial to ECEC practice, as beliefs direct the initiation and implementation of educational processes (e.g. Pianta et al. 2005). Chinese and US teachers' beliefs are similar, emphasizing child-initiated learning, teacher-directed learning and broad, integrated curriculum. On the other hand, American and Chinese teachers are quite different in the degree to which they endorse many teaching beliefs. Chinese teachers are more likely to endorse teacher-structured, practice-oriented instructional approaches. US teachers are more likely to endorse less formal, less structured, child-initiated learning approaches (Wang et al. 2008).

Building teachers' individual and collective capacity to promoting children's learning proves critical (Hall and Hord 2015; Stoll et al. 2006). Capacity is understood as "the skills, motivations, knowledge, and attitudes necessary to implement innovations, which exist at the individual, organization, and community levels" (Wandersman et al. 2006, p. 789). An innovation is understood as a planned change intended to improve practice. Developing professional ECEC networks with a system of training and external consulting may encourage tutoring and strengthen the status of the profession (OECD 2015). Documentation of educational practice and children's development is highly recommended (OECD 2015). International research has been putting effort into developing reliable and valid instruments to measure ECEC quality. ECERS-R (Harms et al. 1998) and CLASS (LaParo et al. 2012) have been widely used in international research. 


\section{The ECEC system in diverse cultural contexts}

Across Europe, there are many similarities in relation to the design and implementation of each ECEC curriculum, although the cultural values and wider understanding of childhood differ in each country, region and program. Despite a large degree of consensus on the broad developmental domains that are addressed in ECEC, significant differences exist on the space that is given to academic learning (Laevers 2005). In some countries literacy and numeracy take a dominant position and children's early learning experiences tend to be predominantly focused toward preparation for schooling. By contrast, curricula in other countries tend to be reluctant to introduce formalized learning experiences in the early years (European Commission 2014). Research shows that children's school readiness depends not only on their cognitive skills, but also on their physical, mental and emotional health and ability to relate to others (Hair et al. 2006). In England, learning and development in ECEC institutions is implemented through planned, purposeful play and through a mix of adult-led and child-initiated activity. As children grow older, and as their development allows, it is expected that the balance will gradually shift towards more activities led by adults, to help children prepare for more formal learning. Practitioners observe children to understand their level of achievement, interests and learning styles, and to then shape learning experiences for each child. Supervision should foster a culture of mutual support, teamwork and continuous improvement in the staff. The staff is supposed to cooperate with parents, exchange information and guide them (Department for Education 2017). Australia has a 632 pages long guide with standards for the ECEC institution and questions to reflect on regarding the standard areas. In Australia, building positive relationships between educators and children is prioritized to help children feel secure, freeing them to explore, play and learn, offer opportunities for children to learn how to interact with others, respect others' rights, be appropriately assertive and caring (Australian Children's Education and Care Quality Authority 2017, Standard 5.1 Relationships with children). Currently, China has no nationwide evaluation standard for early childhood education quality (Qi and Melhuish 2016). A balanced approach to teacher-directed whole-group teaching and child-initiated free play was the best approach to quality ECEC curricula in China (Hu and Szente 2009). Nevertheless, both Chinese teachers and parents primarily rely on and value the use of teacherdirected whole-group instruction to teach knowledge and skills for each curricular domain (Hu 2015). In Texas, parents of 3- and 4-year-olds can access child care and education programs in several settings. The purpose of the pre-kindergarten program is to develop the skills necessary for success in the school curriculum, including language, mathematics, and social skills. Children are eligible to participate in Head Start programs if they come from low-income families. The program emphasizes the involvement of families and the local community (Legislative Budget Board 2007). In Chile, participation rates of children under the age of 3 in formal childcare arrangements is only 18\% (OECD 2016). The majority of children aged 4-5 from poor or extremely poor families do not participate in ECEC services due to the belief that they are too young. The current overemphasis on "school readiness" in the curriculum has the risk of 
underestimating children's socioemotional development. One concern is that children are increasingly losing their childhood as their cognitive development tends to be overemphasized and they often spend much of their activity time sitting at the desk rather than playing and enjoying different activities (Umayahara 2006). In Canada, the ECEC teacher provides a play-based, developmentally appropriate learning experience and materials that enhance the development and learning of all children, provides a balance between educator-initiated activities and child-initiated activities, uses reflective practice, planned observations, and a range of assessment strategies to identify the strengths, needs, and interests of individual children (differentiated learning), provides parents with ongoing communication on their child's progress in all developmental areas through information/orientation sessions, parent-educator conferences, progress reports, portfolios, etc., works cooperatively and collaboratively with families, continues to develop expertise through on-going professional training. The ECEC environment should provide a place for children to feel safe and supported to take risks, cooperate with others, and become confident, independent learners (Prince Edward Island Department of Education and Early Childhood Development 2008).

In Russia the ECEC system is seen today as one of the factors in strengthening and preserving children's health as well as improving the demographic situation in the Russian Federation. The functioning of the Russian preschool education system is regulated by the Law of the Russian Federation (UNESCO 2010). The ECEC is divided into diverse groups to serve children's needs. Children are taught cultural and health skills, a tolerant attitude to the people around and loyalty towards their country. The educational staff includes educators and senior educators, music teachers, physical education teachers, psychologists, speech therapists and supplementary education specialists. The content of preschool education must cover all areas of the individual preschool child's development: social and personal, intellectual, physical, artistic and aesthetic. Every day, parents receive information about their children's achievements. They may discuss with the educators any problems worrying them and receive qualified advice (UNESCO 2010).

\section{The Norwegian ECEC context}

The Norwegian ECEC profession highlights learning through play og social interaction, and is less focused on schooling or formal learning. Still, the children are supposed to develop knowledge and skills within seven learning areas which are substantially the same as the subjects they will meet in school (Ministry of Education and Research 2017). The ECEC institution in Norway is supposed to promote democracy in which everyone is allowed to express themselves, be heard and participate. The staff must work in agreement with parents. The Norwegian ECEC system struggles with a shortage of qualified staff which may undermine process quality (e.g. the quality of adult-child-interactions) (OECD 2015). Professional capacities acquired through professional development and training are required for ECEC staff to plan and implement meaningful, high-quality interventions (OECD 2015). Thus, capacity-building efforts and research in the Norwegian ECEC context is increasing. Norwegian ECEC teachers study 3 years at 
a university or university college to earn a degree. The pedagogue norm requires one ECEC teacher per 7-9 children under the age of 3 and one ECEC teacher per 16-18 children over the age of 3 when children attend more than $6 \mathrm{~h}$ a day. Usually untrained staff is present in addition to the ECEC teacher (OECD 2015). Having access to a place in the ECEC institution is a statutory right for children in Norway, though taking part is voluntary. In 2013, $90 \%$ of children between the ages of one and five, including $97.5 \%$ of 5-year-olds, participated in ECEC institutions in Norway (OECD 2015). Norway has committed to the early intervention and social inclusion of every child (Report no. 16 to the Storting 2006-2007; Report no. 18 to the Storting 2010-2011). Nevertheless, there are significant quality disparities among Norwegian ECEC institutions and many children with special needs do not receive the help they need in time (Report no. 19 to the Storting 2015-2016).

Developmental trajectories of physical aggression in a population-based birth cohort suggest that the peak frequency in physical aggression for most humans is somewhere between 2 and 4 years of age (Côté et al. 2006). Tremblay (2010) highlighted the need for establishing clear norm-systems to relearn disruptive behaviors from an early age, emphasizing early intervention to prevent lifelong aggression and exclusion processes into adulthood.

This article considers the innovation process in seven Norwegian ECEC institutions that are phasing-in the program Being Together (BT). BT is an early intervention approach to the promotion of social and emotional development in preschoolers (aged 1-5 years) by implementing an authoritative adult style in the institution (e.g. Baumrind 1991; Ertesvåg 2011; Wentzel 2002). The authoritative adult attempts to build a warm and predictable relationship with the child, while communicating clear expectations, rules and structures in the learning environment, so that the child may develop a secure pattern of attachment with the caregiver (Bretherton and Parke 1992). An authoritative adult style differs from three other adult styles illustrated along two axes (high or low level of warmth and control); authoritarian (low warmth and high control), permissive (high warmth and low control) or neglecting (low warmth and low control) (Baumrind 1991). Baumrind (1991) found that the authoritative adult style promoted positive behavior and decreased negative behavior in children. The authoritative parenting style has been adapted to the teaching style (e.g. Wentzel 2002). Teacher-pupil relationships characterized by warmth and clear expectations influenced positively on the pupil's learning achievement and social adjustment (Hamre and Pianta 2005; Walker 2008). This approach seems consistent with the mix of adult-led and child-initiated activity (similar to England and Canada), adults listening to children, evolving respect, empathy, social skills and positive interactions (similar to Australia) in the ECEC learning environment.

The BT program was initiated by the Being Together foundation in cooperation with the Office of the County Governor of Vest-Agder, Norway and the National Centre for Learning Environment and Behavioural Research in Education, University of Stavanger, Norway. The Department of Education, University of Agder, Norway was responsible for the follow-up research and evaluation. The innovation was funded by the Norwegian Ministry of Education and Research. The aim of the program was to strengthen ECEC institutions' ability to prevent 
challenging behaviors at an early stage. Positive interactions between adults and children are crucial for children's early learning and development (Downer et al. 2009).

This study draws on empirical data from staff members responsible for 3- to 6-year-olds in seven ECEC institutions taking part in the innovation. BT has involved more than 1000 Norwegian ECEC institutions and around 3000 supervisors from 50 municipalities, making it an extraordinary, nationwide capacity-building initiative in ECEC institutions in Norway. The main objective of this study was to investigate the possibilities and challenges in the ECEC institutions' implementation of the BT program.

This paper is based on the results gathered by the author during the first year of implementation. The results were gathered from: (1) focus group interviews with the project groups who were responsible for creating the capacity in each ECEC institution; (2) semi-structured interviews with the BT supervisors; and (3) in-depth interviews with the project leaders who developed the idea of BT.

\section{Being Together (BT) intervention}

\section{Principles}

The key principles underlying the BT program are: (1) Authoritative adults build quality relationships with children and take control when norms are threatened or ignored. Authoritative adults, like authoritative parents (Baumrind 1991; Ertesvåg 2011; Pellerin 2005; Walker 2008; Wentzel 2002) approach children with warmth, tolerance and openness in the relationship, while establishing interpersonal values, norms and standards in social interactions. (2) The intervention is broad, including all staff members and parents in participating ECEC institutions, and eliciting commitment from local educational authorities characterized by a collective orientation. BT is also broad in terms of preventing social and emotional difficulties in children by adapting the methods to a child's individual needs. (3) Consistency is achieved when ECEC staff act in accordance with key BT principles regardless of contextual conditions, and when the staff commit to a shared vision, attitudes and practice that underpin the program. Consistency is promoted among ECEC staff with or without formal training, using common learning measures, and through the implementation of joint attitudes and actions through collective orientation. (4) Continuity is key to the success of BT. Participants in the innovation program commit to remain loyal, and to work systematically with the three other principles (mentioned above) to reach long-term effects and sustainable development. When new actions are to be implemented into the BT program, staff members are to find ways of including them with former actions. New staff members are included in the learning process, committing themselves to the key principles to continue the program over time.

ECEC institutions work on developing and implementing the four key BT principles during a 12-month period, with the goal of instilling into the staff a common understanding and a shared loyalty toward the BT vision. During the 
1-year program, the ECEC project groups are required to make goal-specific, timescheduled plans, for the implementation of new activities and the organization of interpersonal interactions both on the playground and inside the institution. Staff members are to make the BT booklets and materials available to children, parents and visitors. They are also to promote the BT principles at parent-teachers' meetings and in colleague tutoring groups.

The key principles are grounded in aggression theory (Crick and Dodge 1994; Dodge and Coie 1987; Dodge et al. 2006; Tremblay 2010), communication theory (Bateson 2000), symbolic interactionism (Mead and Morris 1934), bioecological theory (Bronfenbrenner 1979, 2005), social learning theory (Bandura 1986), implementation theory (Blasé et al. 2012; Domitrovich et al. 2008, 2012; Durlak and DuPre 2008; Fixsen et al. 2005; Fullan 2007; Greenberg et al. 2005) and organizational theory including theory on professional learning communities, collective orientation and transformational leadership (DuFour et al. 2005; Hargreaves and Shirley 2009; Leithwood and Beatty 2008; Senge 2006; Stoll et al. 2006; Stoll and Seashore 2007). The theoretical underpinning emphasizes the relationship between high-quality interactions among participants and individual and collective development.

\section{Content}

During the 1 year implementation phase, staff members from different ECEC institutions participate in four 1-day seminars that cover the core components of the intervention: (1) aggression and its causes and intervention; (2) the authoritative adult style, and development of quality relationships between children and adults (LaParo et al. 2012); (3) communication and teambuilding; (4) implementation, organizational learning and capacity-building. The leader of the ECEC institution carries the main responsibility for holding to the program, and a project group shares the daily responsibility of implementing the program. The project group includes the leader and other key ECEC personnel. The group leads the work toward the vision, preparing the project plan with clear goals and measures in agreement with the staff group. The project groups network with several other ECEC institutions, to exchange knowledge and experiences gained during the implementation phase. All staff members regularly attend colleague tutoring groups during the implementation period. Several of the ECEC institutions invite the BT project leaders to lecture at parent-teacher meetings on the authoritative adult and building quality relationships.

BT supervisors normally represent the leaders of the ECEC institution. They have their own tutor training program. The supervisors attend a 4-day seminar that covers the principles of the program, local responsibility, management and leadership. Supervisors are to give their staff the knowledge and tools needed to support the implementation process in their ECEC institution. Thus, the supervisors are important driving forces in the innovation program (Fixsen et al. 2005).

The BT project leaders have developed a support system for participants, which includes both child and adult educational materials. Four booklets deal with the four seminar themes for staff members mentioned above. Parents are given their own 
book about the authoritative adult style, to improve interactions with their child at home. Parent supervision is widespread practice across cultural ECEC contexts previously outlined in the introduction.

\section{Conceptual framework}

The aim of this paper is to examine the conditions in ECEC institutions that help to successfully phase-in the BT program principles during the 1 year of implementation. I focus on conditions that can affect successful implementation. First, I discuss the concept of implementation, and then elaborate on collective orientation, leadership and on individual and organizational conditions.

\section{Implementation}

Implementation is putting a theory into practice in a real-life setting (Fullan 2007). This is the crucial aspect of the innovation process, requiring much effort to succeed. If the quality of the implementation is weak, the vision will not become part of the everyday life of the institution, with little or no effect on professional practice (Greenberg et al. 2005; Domitrovich et al. 2012). Durlak and DuPre (2008) argue that the quality of the implementation depends on the extent to which the intervention follows its intentions. The quality of the implementation depends on how the intervention's content or core issues are communicated to the staff (for instance, through the training of staff members, and the training of external supervisors in the key principles that are to be implemented in the BT intervention), and the strength of the support system (for instance, having access to an external supervisor, a model for colleague tutoring, project leaders and materials for children and adults, such as in BT). This makes it easier to transform principles and core components into practice (Blasé et al. 2012; Durlak and DuPre 2008; Greenberg et al. 2005).

Fixsen et al. (2005) underline the importance of training, to succeed in implementing the core components and procedures in the planned change. Practicing the key skills of the intervention through different methods is necessary for putting the theory into practice in the institution (Blasé et al. 2012; Domitrovich et al. 2012; Greenberg et al. 2005). Fixsen et al. (2005) suggest training methods based on work performance. Participants receive supervision while practicing the innovation skills, and then reflect on their experiences. Training is intended to provide greater clarity of the core components (Fullan 2007). In BT intervention, the main goal is to develop authoritative adults. Methods should be collectively orientated when the goal of a program is a common vision.

If there is a large discrepancy between the planned innovation and the actual change being implemented, the quality of the implementation will be weak and the change poor (Domitrovich et al. 2012; Greenberg et al. 2005). Loyalty to the core elements in the innovation has the strongest impact on the quality of the implementation and human motivation for change (Durlak and DuPre 2008). Because of this, it is vital to strengthen participant responsiveness and readiness for 
the change process, by working from the bottom up, or by focusing on user participation.

\section{Collective orientation}

Creating staff capacity through a collective orientation appears to facilitate sustainable improvement. The learning community is a vehicle for professional learning and school development (Hall and Hord 2015). Stoll et al. (2006) argue that, to find ways of consistently enhancing children's learning and ensuring the continuation of change when implementing a new practice, school communities should cooperate and learn together. From the outline of the diverse cultural ECEC contexts in the introduction, approaches to ECEC seem to emphasize the importance of each ECEC institution developing strong relations with children and parents, but to a lesser extent prioritize cooperation and learning across ECEC institutions. Professional learning communities should constantly seek new knowledge, and share this knowledge, to continuously improve ongoing practice in accordance with this knowledge (Hargreaves and Fullan 2012). The assumed results are professionals who more effectively develop positive learning environments for the wellbeing, learning and growth of children. Common learning, in which individuals adapt the same theory and achieve a shared vision through joint competence and tutoring, is seen to create an inter-subjectivity or a common, articulated professionally justified practice among staff members, which in turn strengthens the motivation to work toward the vision (Senge 2006). To make change happen, BT intervention focuses on colleague tutoring as a way of articulating tacit knowledge. BT intervention also analyzes the interactions between adults and children through external observation. Systematic professional dialogues, in which staff members document, exchange and analyze their daily interactions with children in the ECEC institutions, is intended to expand the perspectives of the BT participants (Bateson 2000). Through each staff member's reflections on their own actions, attitudes, knowledge, understanding and prior experience gained in colleague tutoring-and those of their colleagues, the capacity of the ECEC staff is assumed to grow through the BT innovation.

\section{Leadership}

Leadership is a critical factor in developing collective processes and common learning in organizations (Fullan 2007). A leader is expected to stimulate colleagues' professional capital through cooperative processes. As a staff group works toward higher professional capital, commitment and enthusiasm rise within the group, which motivates the staff to gain greater knowledge and learning (Hargreaves and Fullan 2012).

Leithwood and Beatty (2008) highlight four crucial elements in directing organizational learning and in improving student outcomes. First, it is crucial to set a direction in the professional mandate by identifying key elements, theories and visions that need to be implemented in the educational work. Second, focus needs to be placed on the development of people, which means that a leader must find the right balance between supporting and challenging his or her group of staff. It also 
requires that the leader be a good role-model, and for the leader to produce pertinent direction based on key issues. Third, directing organizational learning requires the redesign of the organization, meaning the reconstruction of the common culture among employees, so that no sub-group or individual are left isolated. Staff can profit from receiving guidance from a network of people working with similar issues, in order to exchange experiences and ideas in how to create professional learning communities (DuFour et al. 2005). Fourth, management of the instructional program is mentioned. It is crucial to ensure that the innovation will be taken seriously. This is done by placing enthusiastic and competent people in charge of the staff group, who follow-up the activities in the implementation process and discourage distractions that arise in the process (Leithwood and Beatty 2008).

\section{Individual and organizational conditions}

Flaspohler et al. (2008, p. 182) associate the construct of capacity with "successful change in practice and/or implementation of prevention". The authors delineate the concept of capacity into two dimensions: level (individual, organizational, and community levels) and type (referring to general and innovation-specific capacity). The authors argue that focusing on several capacities may help in approaching an understanding of capacity-building, and supporting implementation processes which aim to adopt new practices or adapt existing ones. The concept of competence is closely related to capacity. Competence is measured as a personal characteristic or a human capability consisting of knowledge, a single skill or an ability (Hoge et al. 2005). Individual capacities are motivation, personal values and attitudes, prior experiences and formal educational background. Self-efficacy beliefs, or the extent to which people believe they could implement core issues and affect children's learning and development, affect staff behavior (Bandura 1986). High individual self-efficacy may produce actual capacity and raise the collective self-efficacy (Leithwood and Beatty 2008). Organizational capacity deals with an institution's infrastructure, environment, leadership and resources. Capacity-building should focus on both the individual and organizational level simultaneously. When the innovation is anchored at the community level, it facilitates cooperation between institutions (Flaspohler et al. 2008). Innovation-specific capacity deals with the individual and organizational readiness to implement an intervention. Strong support systems make it easier to phase-in core issues.

Implementation of change processes may provoke opposition in the staff group (Burke 2008). If loyalty towards capacity-building is low, it will be hard to achieve a shared vision or decide on core values for the entire group.

\section{Method}

\section{Sample and data collection}

The ECEC staff members of seven randomly selected ECEC institutions from different municipalities in southern Norway participating in the BT program agreed 
to take part in focus-group interviews at the beginning and before the end of the first year of implementation. There were 21 pilot institutions in total, and for each municipality we randomly chose the name of an institution that would participate in the follow-up study. Each of the seven focus groups consisted of five to seven staff members with a variety of educational backgrounds and roles in the institution: assistants, children and youth workers, the institutional leader and ECEC teachers. The aim was to obtain the perceptions of employees irrespective of their formal educational level, as it was considered important to include everyone in the same capacity-building program. The focus-group interviews focused on the staff's experiences with the intervention and the implementation of the authoritative adult style in the institution: how it influenced adult-child-interactions, how they used external supervision and colleague tutoring, and how the seminars and educational material for both children and adults in the innovation helped them to put the theory into practice.

Nine external supervisors who mentored the ECEC institutions were interviewed at the beginning and near the end of the first year of implementation. This was done mainly in pairs using a semi-structured interview guide, focusing on their supervision of ECEC staff members, as well as how they attempted to strengthen a sense of responsibility in the staff group to stick to the plan and implement the core issues of BT. The mentors also talked about the tutor training they went through.

In-depth interviews were carried out with each of the BT project leaders, to become familiar with their backgrounds, their intentions for developing the concept of the intervention and their roles in the implementation process. The interviews aimed at providing an in-depth understanding of a selection of informants' experiences during their participation in the innovation. Data was collected and then analyzed to discover if implementation of the core issues of BT resulted in capacity building and change processes in the ECEC institutions involved.

\section{How the interviews were conducted}

The focus-group interviews were carried out twice by two academic staff members from the University of Agder (including the author) at the participants' workplace during the first year of implementation, in October/November 2011 and in April/ May 2012. One of the researchers took the main responsibility for posing the questions and leading the discussion on specific themes, while the other made notes on the process and the body language of the participants. The observer also became involved in the discussions to ensure that each participant shared their perceptions, or to obtain clarification if something was unclear. It became challenging to follow a line of inquiry when all the participants talked at the same time and made several comments on each topic. Nevertheless, the strength of this method is that it brings out different points of view on an issue (Kvale and Brinkmann 2009).

Before the interviews, the researchers visited each institution to get to know the participants and their context, and to explain the purpose of the research. The participants gave their informed consent to take part in an interview, in accordance with the ethical guidelines given by The National Committee for Research Ethics in 
the Social Sciences and the Humanities (NESH 2006). The study was approved by the Norwegian Social Science Data Services (NSD). The participants could withdraw their consent at any time and have all their data deleted. Data is kept anonymous in every publication relating to the project, and no names of individuals or institutions are revealed.

The supervisors were interviewed in the same two periods, mainly in pairs depending on who cooperated most with each other and were from the same area. The supervisors were, for practical reasons, interviewed during two BT courses for the ECEC staff, one in the autumn and the other in the spring in the first year of implementation. The project leaders were interviewed individually at the Governor's house in the County of Vest-Agder. The focus-group interviews lasted about $45 \mathrm{~min}$ each, while the other interviews lasted about $30 \mathrm{~min}$. The interviews were recorded on an iPod.

\section{Data analysis}

Content analyses (Patton 2002) were used to analyze the interview data. The interviews were transcribed word-for-word from the iPod recordings. The transcribed interview data were organized and analyzed in the qualitative software program NVivo (Richards 2002). The focus areas in the interview guides were identified as nodes in NVivo, together with new meaningful themes that appeared during the interview sessions. The following issues were highlighted in NVivo as success criteria in the implementation process: (1) Strong support systems; (2) Powerful delivery of core principles; (3) Highly involved leaders; (4) Systematic project plans; (5) Systematic reflection groups among staff members; (6) Written documentation and evaluation, and; (7) Formal educational qualifications of staff members.

\section{Results}

The evaluation study aimed to identify possibilities and challenges in the implementation of the key principles of the BT program in seven pilot ECEC institutions. As indicated in the conceptual framework presented in this paper, I investigated four areas regarding successful implementation at the end of the program period: (1) implementation; (2) collective orientation; (3) leadership; and (4) individual and organizational conditions. Participants' quotations are identified by indented paragraphs in the text.

\section{Implementation}

One core component of BT is innovation theory, which emphasizes the implementation process. Supervisors were taught and then practiced methods that were intended to facilitate the implementation of the program principles into the ECEC institutions during the tutor training program. They guided the staff in the use of these methods. The staff were given a question, such as, 'What characterizes quality 
interactions between adults and children? Identify three points'. Everyone reflected individually for 5-10 min before sharing their key points to a group of four people. Group members then shared their points and reflected on the ideas for 20-30 min. Each group agreed on three key points, which they presented in plenum for 20-60 min including time for discussion.

The BT supervisors highlighted ECEC staff's need to acquire more knowledge about implementation theory at the start of the program. They also emphasized the importance of loyalty to the success of the innovation:

The entire staff must be included [in the project] from the very beginning, and must be loyal to decisions made. Management should focus on program principles. ECEC leaders are to expect results and require all colleagues to take responsibility in the implementation. However, staff members must be convinced that the program truly helps them in coping with challenging behavior, while improving adult-child relationships. Everyone must be aware of the success criteria and risk factors when implementing a BT program into the daily life of an ECEC institution (supervisor).

The supervisors viewed themselves as supporters in the staff groups' implementation process:

I am responsible for helping the staff understand the theory and turn it into practice, to reflect on their behavior, to use the material constructively, to raise competence in the institution, and structure the conversations in the ECEC institution (supervisor).

The ECEC teachers with formal training emphasized how essential their discussions were during colleague tutoring in reaching a common understanding in the implementation process. Each person had to make observations and write practice histories from what they had observed, both in peer interactions and interactions between adults and children. The guidance documents used for colleague tutoring were based on actual episodes observed in the institution:

The practice histories are excellent for reflecting on the child's perspective what are their concerns, interests and thoughts? (ECEC teacher with formal training).

Those ECEC institutions without a specific plan for implementing the key principles into daily life did less training and preparation for the change processes. They may have not invested enough time in the initiation phase of the intervention and lacked a strategy for turning theory into practice. Staff members in these institutions seemed to place responsibility for this onto their project leaders, though it was never intended for the project leaders to make goals for the ECEC institutions. The project leaders, however, made it clear that the staff groups were responsible for implementing the innovation. It was challenging that some staff groups appeared not to be completely committed to the program principles:

I found it very hard to initiate the implementation. We'd probably do things differently if we could do it all over again. We asked the project leaders to 
draw posters with specific goals so we could hang them on the walls of the institution (ECEC teacher with formal training).

The interviewees talked about challenges in reaching a common understanding and working toward the same goals in BT. Temporary staff did not participate in the seminars and did not know the key principles in the program. Implementation was time-consuming, and the staff struggled with prioritizing the program ahead of other plans in the institution:

How could we supervise temporary staff members to act in this way? (ECEC teacher with formal training).

We planned to work with BT on Tuesdays and Thursdays, but it just didn't happen. It was too much too often. We couldn't do it twice a week for an entire year -it was just too much! (ECEC teacher with formal training).

The teachers with formal training mentioned the dilemma of staff members without formal training holding different values and norms from their own upbringing, making it challenging for the entire staff group to adopt the authoritative adult style. Not everyone was enthusiastic about changing and evolving their knowledge:

There are so many different adults - how could we implement this in everyone? (ECEC teacher with formal training).

We've moved very slowly, because it's very important to move everyone together toward a shared understanding (ECEC teacher with formal training).

The teachers with formal training emphasized that the support system was crucial in managing the implementation of the key principles. The project leaders explained why support systems are vital when implementing an intervention:

Without a support system, it is difficult to implement anything. If we focus only on the project and not on the implementation, the effect will be poor - it won't create any sustained change (project leader).

The booklets that presented the core issues of BT were easily accessible to the entire staff group, irrespective of their formal educational level. The booklets helped everyone to learn the innovation's theoretical framework, containing clear explanations of key concepts in a simple format that made it easy for everyone to understand the message. The participants said that the booklets motivated them to read more. The BT seminars had inspired the participants in their implementation process:

They're great! I always go home thinking: It was such a pity that not everyone was there! Because it's important for everyone to have the same experience (ECEC teacher with formal training).

There were obvious differences between those in the staff group who attended the seminars and those who did not. The institutional leaders described the staff who attended the seminars as being more engaged in the change process than those who 
did not attend. However, the differences between staff members with and without formal training was the main challenge in the capacity building. It was a real paradox in BT, that those with the least theoretical knowledge were seldom sent to the seminars because they were the ones who had to take care of the institution while the skilled staff members were away at the seminars. Staff members who spend most time with the children — and who needed the capacity-building mostwere given the least instruction in BT. This qualification diversity was even greater during the first year of implementation, until the project leaders continued the capacity-building by offering ECEC staff members without formal training their own seminars.

A core component of BT is to develop the ECEC staff's ability to implement an authoritative adult style as well as high-quality interactions in the institution. Participants were committed to phasing-in the authoritative adult role through a collective effort. The staff needed time to become familiar with the concept of the authoritative adult (high warmth/high control) which they sometimes confused with the concept of an authoritarian adult (low warmth/high control). Several staff groups conceptualized authoritative as 'warm and clear' to prevent misinterpretations. They often spoke of the 'cross', referring to Baumrind's (1991) typology representing the four different adult styles with high or low levels of warmth and control in a relationship:

We often discussed the authoritative adult role. What does it mean? We needed to concretize and operationalize the concept to make sure we understood it right. We used the 'cross' to show where we should stand. We've done our best, and I hope most of the staff members understand it now. But you can never get everyone to go along with you (ECEC teacher with formal training).

The staff found it hard to balance between building warm relationships and setting limits for the children. They wanted someone to tell them exactly how to do this:

I miss having a recipe for the adult role, because I think the essence of the program is about changing the adult style (ECEC teacher with formal training).

Both teachers with and without formal training felt that the interactions between adults and children were more empathic after they focused on building stronger relationships by using banking time-systematic quality time between a child and an adult that focuses on the child's needs and interests (Pianta 1999). They claimed that the implementation of the authoritative adult style had resulted in less use of discipline and time-outs with the children. When the adults communicated their expectations more clearly, agreed about their reactions and decided on some common strategies in interacting with the children, the learning environment became more predictable for the children and their behavior became less challenging. The staff discussions on the authoritative adult style were identified as the most influential aspect in working towards common goals in interacting with the children: 
We wrote down the names of the children we found it harder to relate to. The way we worked afterward was fantastic. We discussed it three weeks later. Many of those children had changed dramatically, because we tried to identify their strengths and found good arenas for positive interactions (ECEC teacher without formal training).

\section{Collective orientation}

The participants met at seminars during the implementation period. The staff groups reflected on the content, explained theory to one another in small groups and exchanged ideas on how to implement the key principles into daily practice. Participants felt inspired when they gathered together from different ECEC institutions:

We really enjoy getting together. Everything is new to us, and it helps to learn from other staff groups implementing the same content, exchanging experiences and ideas with them, and hearing how it's going for them (ECEC teacher with formal training).

The BT project leaders highlighted the use of common learning for all staff members within and between ECEC institutions, in order to reach joint, evidencebased work performance:

As they transform theory into practical daily life, learning happens (project leader).

When each staff group gains the same understanding, embraces the same adult role and works toward a shared vision, the institution will develop (project leader).

After the staff groups had acquired some common values, they were able to communicate their goals more clearly to the outside world, phrasing their values and practices in terms of the overall institutional plan:

When people asked, 'What's special about your institution?' I used to wonder how to answer. But now we've got something special. This is the focus of our institution, these are our values. It's very specific (ECEC teacher with formal training).

If one colleague experienced a challenge with a child, the participants helped the colleague to find his or her own solution on how to act in an authoritative way. The tutoring made both teachers with and without formal training more open, and they became used to giving each other constructive feedback:

It's not often we have time to be as open and honest with each other as we are during the colleague counselling sessions. How to set limits respectfully... It's now possible to say to a colleague in a challenging situation with a child; 'Did you notice that you crossed the line now? What happened?' (ECEC teacher without formal training). 
The staff groups invested time in practicing the knowledge they received at the seminars and taught to them by their supervisors during the implementation phase. They worked to implement the theory into their daily routines:

You have to constantly practice to get to know the material and to really understand the theory. Then one day, faced with a challenging situation, you say to yourself, 'I can use that book!' (ECEC teacher with formal training).

\section{Leadership}

One project leader felt that the ECEC institutions taking part in the capacity building lacked decisive management at the beginning of the program:

I want to see clearer leadership in ECEC institutions. They do not have leaders who will take responsibility for the implementation (project leader).

Several of the ECEC leaders expected everyone in the staff group to read the BT booklets containing the key principles. They gave them an hour each week at work to read:

To reach a common goal, everyone must read the same theory (ECEC teacher with formal training).

The BT supervisors appreciated the tutor training they had undergone. They felt that the courses taught them about implementation theory and transformational leadership, which helped them in supervising the ECEC staff. They highlighted the importance of giving staff members time to embrace the innovation and decide how to manage the implementation. It had been crucial for the external supervisors to work from the bottom up with the staff members, taking each ECEC institution's unique context into consideration in the tutoring, instead of working top-down by giving expert advice to the staff groups-no matter what context they came from. Thus, the supervisors ensured that all employees felt they owned the principles of the intervention and found them helpful in their daily practice:

The entire ECEC institution must own the project (supervisor).

\section{Individual and organizational conditions}

The main goal of the BT intervention was to create capacity in the ECEC staff and promote supportive interactions with the children through collective efforts. Staff members worked to achieve a common understanding of their professional mission by identifying the key knowledge, skills, motivation, values and attitudes needed in their work with the children in the institution. One of the project leaders felt that the hierarchy between the ECEC teachers and assistants had been a challenge in the implementation process:

The hierarchical system in several of the ECEC institutions became obvious when staff members came to me saying: 'The leader group found out how to present this to the rest of the staff'. I was surprised, because I thought 
everyone should implement everything simultaneously. The ECEC teachers had more power than I was aware of (project leader).

BT had been warmly welcomed, especially by the ECEC teachers. Most of the participants said that they had learned much by taking part, and that they had changed their behavior and attitudes after implementing the authoritative adult role:

I've changed. I see things differently. I've worked in this institution for 40 years, and I treat the children with more respect now (ECEC teacher without formal training).

Both teachers with and without formal training felt that having access to an external supervisor made them more structured and committed to capacity-building. They needed a supervisor who would follow them up and motivate them to remain loyal to the intervention:

It's like, 'We need to pull ourselves together and get ourselves ready - Kari is coming! We have to fulfill the requirements of the guidance document!' (ECEC teacher without formal training).

The supervisors felt that some of the ECEC staff groups needed a great deal of support to follow the implementation plan:

I didn't expect that I'd have to push the staff to such an extent. I had to motivate them all the time: "How far have you gotten?" I thought they would ask me questions; I thought they would own the program a bit more. After all, it's the project leaders in each ECEC institution who are supposed to run this (supervisor).

Institutions with a systematic project plan with clear objectives and measures, a time-scale and a structure for evaluation and adjustment, were more loyal toward the vision of the innovation than those who did not have a written plan to guide them through the implementation process. It was important that the project plan remain clearly connected to the institution's annual plan for the plan to be implemented. The staff also needed to 'go for it', commit their time and energy into the program in order for the implementation phase to succeed:

When an ECEC institution commits to the BT program, the staff must commit to the innovation by starting certain activities in August, continuing with other activities in September, and so on. Otherwise, time goes by without anything getting done (supervisor).

It was necessary to work systematically and over a long period to time to obtain a shared vision among the staff members. Both teachers with and without formal training felt that there should have been more focus on staff members who didn't have formal professional training, ensuring that they received the same information the ECEC teachers and leaders with formal training had received. 


\section{Discussion}

The BT innovation's emphasis on collective orientation, common goals and a joint adult role in interaction with children may promote evidence-based standards in ECEC and a consistent practice which is crucial to prevent social-emotional problems in children. The Australian ECEC curriculum consists of quality standards. Colleague supervision which is used as a training method in common learning processes in BT is also highlighted in the English ECEC system to promote a culture of mutual support, teamwork and continuous improvement in the staff. Reflective practice from Canadian ECEC is consistent with the BT ideas. Chinese people rely on and value the use of teacher-directed whole-group instruction to teach knowledge and skills. This differs from the BT program's focus on so-called banking time or quality time between an individual child and an adult to build up strong relationships based on the child's needs and interests.

This study focuses on possibilities and challenges in the ECEC institutions' implementation of the key principles of the BT innovation. Given the results, the success factors in the implementation process during the 1-year project period in the seven ECEC institutions were: (1) strong commitment to the authoritative adult style, (2) strong focus on the implementation process, (3) advanced support systems, (4) highly involved leaders, and (5) a collective orientation. Both enablers and challenges are discussed in the following.

\section{Strong commitment to the authoritative adult style}

The ECEC teachers with formal training in particular became strongly engaged in the authoritative adult style, finding it helpful for their work performance. Professionals without formal training who were unwilling to change and evolve their knowledge made it more difficult for the institution to adopt the authoritative adult style.

When participants in the innovation shared the responsibility of implementing the authoritative adult style (Baumrind 1991), it meant having a joint understanding of how to combine warm relationships with clear structures, norms and consistent reactions toward the children, and welcoming colleagues' constructive input while practicing the theory. It was seen as a challenge for the institution to adopt the authoritative adult style as the theory did not tell them the exact way of building relationships or setting standards in interactions with the children. Some staff groups struggled a lot to define concrete goals and actions for the authoritative adult's behavior.

Both teachers with and without formal training claimed that capacity-building had improved their observations and interactions with the children. They wrote professional narratives from everyday interactions with the children and used them as guidance documents in colleague tutoring sessions. 


\section{Strong focus on the implementation process}

The innovation emphasized the focus on implementation during the change processes in the ECEC staff groups. The self-efficacy of each staff member and the common self-efficacy of the staff group, had been crucial in the implementation process (Leithwood and Beatty 2008). It was crucial that the project leaders and supervisors provided the participants with the knowledge they needed to implement change, to make long-term plans, and to build the motivation they needed to achieve lasting improvement for the children and the staff. It was thus the ECEC staff who were responsible for integrating the program principles into existing structures of the institution (e.g. Domitrovich et al. 2012).

Through systematic colleague tutoring sessions and other collectively-orientated training methods, the ECEC staff were brought together by a new set of shared values and by a common vision for how they should interact with the children. These methods, together with the support from their ECEC leader and the supervisor, the knowledge gained at the seminars, and the educational material they received for adults and children-all worked as the driving force for implementing the innovation (Blasé et al. 2012).

A systematic project plan with clear goals and structures, adjusted to the local context of each institution and known by the entire staff group, had been reinforced in the implementation process. Yet some institutions failed to write a project plan, or if they had, their plan lacked clear goals, measures and assessment criteria. Only a few institutions evaluated their implementation of the BT principles in writing, the others preferring instead to talk about them during their staff meetings. Several staff groups wished their supervisor would have helped them identify not only what should have been evaluated, but also how and when to evaluate. The participants' lack of written documentation and their loyalty to oral communication is not unknown in ECEC institutions. This does, however, make it challenging - both for the children's parents and external controllers-to properly evaluate children's learning processes and a staff group's work performance, goals and assessments. It inhibits any attempt to build a learning organization or a sense of professionalism among ECEC teachers.

\section{Advanced support systems}

BT had a strong support system that raised the possibility of putting BT ideas into practice and increasing the quality of the implementation (Domitrovich et al. 2012; Greenberg et al. 2005). The external supervisors in BT played a crucial role for the ECEC staff to stick to the key principles, to stay loyal to the vision and to move forward. The colleague tutoring model's structure was seen by the participants as overtly time-consuming, but it helped them articulate tacit knowledge in the staff group. The booklets that discussed the theoretical underpinning of capacity-building helped every staff member-irrespective of their educational background-to understand the key issues of the intervention, and helped to create a sense of ownership for the project. 
The delivery of the key principles and core components in BT had been viewed by the participants as strong during the project period. The seminars had prepared the teachers with formal training to put the theory into practice in their institution (Durlak and DuPre 2008; Greenberg et al. 2005). It had been a challenge, though, that not every staff member could attend the seminars, which were held during the middle of the day.

The ECEC teachers felt that the exchange of experiences with other ECEC institutions at the seminars was helpful in the implementation process. They were expected to articulate their understanding of the theory during the seminars. When some in the staff missed the common learning, it made it more complicated to build a common vision, something that is crucial in all innovations (Fullan 2001; Senge 2006; Stoll et al. 2006).

\section{Highly involved leaders}

The BT project leaders had highlighted each ECEC institutional leader's responsibility for the collective learning processes in the staff group. The ECEC leader aimed to build a collaborative institutional culture, in which reflection was encouraged, and where colleagues worked together and supported one another, with the free exchange of ideas and the offering of constructive feedback on each other's work performance (Hargreaves and Fullan 2012). Success in the implementation of the BT principles presupposed the involvement of highly engaged institutional leaders who possessed clear insight into the key principles of the program-and adequate persuasive skills to implement them at their institution. The BT supervisors emphasized the importance of anchoring the innovation at the institution's management level, so that it became a permanent part of the institution's culture. Each ECEC institution was given a project group that oversaw the change process.

Highly involved ECEC institutions managed the instructional program quite well. Highly engaged leaders believed in the key principles and in their staff's ability to implement them into the daily life of the institution. They supported their staff group throughout capacity-building, and fully expected that staff loyalty to the vision would cause the implementation process to succeed. In other words, a key to success for the ECEC institutions' implementation processes had been transformational leadership (Leithwood and Beatty 2008). Leaders had to set a clear direction with a clear vision. This meant that they had to maintain a balance between supporting and challenging their staff when developing their staff group. The leader needed to follow up the activities of the staff group while stopping distractions during the capacity-building process toward organizational learning and improved outcomes of the children (Leithwood and Beatty 2008).

Some ECEC leaders found it hard to build a common culture among the staff members and to prevent sub-groups from developing. To successfully manage the instructional program, the leader placed enthusiastic, competent people in charge of the staff group. The project groups consisted mostly of teachers with formal training. Professionals without formal training would probably have felt more 
responsible and informed during the implementation process if they had been part of the project group.

\section{A collective orientation}

Obtaining a common understanding and a joint practice is a core task for the learning organization (Fullan 2001; Senge 2006; Stoll et al. 2006). BT's focus on common learning and implementation of systematic colleague tutoring in the ECEC institutions, contributed to a greater openness in the staff, causing them to be more aware of their own individual practice theory. It was consequently easier for them to give each other feedback on their work performance. Systematic training on implementing the authoritative adult style resulted in a common educational platform and higher professionalism among staff members with formal training in BT (Fixsen et al. 2005).

Raising self-efficacy (Bandura 1997) among all staff members, irrespective of the diversity in formal educational backgrounds in the ECEC institution, through common learning and a shared vision, was emphasized by the project leaders in BT. These were all done for the soul purpose of supporting and nurturing the learning and development of each child. Even so, staff members without formal training seemed to have had less access to the BT seminars. Consequently, they were less enthusiastic about changing their attitudes and adult style, making it more challenging for the entire staff group to reach a shared vision.

\section{Conclusions}

Early intervention is particularly important to prevent long-term mental health problems in children at risk (Tremblay 2010). ECEC teachers play a key role in providing high-quality opportunities for young children's learning and development. Norwegian ECEC institutions would probably benefit from having more adequate and precise standards for staff quality and process quality (e.g. adultchild-interactions). Further challenges for Norwegian ECEC quality are the lack of reliable and valid instruments to monitor process quality and educational effectiveness (OECD 2015). Thus, more research programs on the nature and effects of Norwegian ECEC quality are needed to develop evidence-based ways to promote the quality of ECEC (OECD 2015).

It is possible to find a convergence toward certain features of ECEC curricula that are regarded as good practice across different contexts (Pramling et al. 2006). Such features include: a curriculum based on principles and values that recognize the rights of the child as a competent human being (UNICEF 1989); a curriculum with principles for sustaining children's development through educational and care practices that are responsive to children's interests, needs and potentials; a curriculum which states explicit goals that address the holistic development of children and strives for an appropriate balance between learning and wellbeing; a curriculum with a strong focus on communication, interaction and dialogue promoting agreed democratic values within a framework of socio-cultural diversity 
(European Commission 2014). Accordingly, creating ECEC teacher capacity should be a constant priority area in promoting quality learning environments in ECEC systems throughout the world.

Increasing evidence from school studies confirm that an authoritative school climate characterized by high levels of warmth and control is associated with positive student outcomes (e.g. Cornell and Huang 2016). The BT evaluation showed that the combination of professional training and coaching (Fixsen et al. 2005; Greenberg et al. 2005; Joyce and Showers 2002) efforts of ECEC institutions in adopting more authoritative teaching strategies (Hamre and Pianta 2005; Walker 2008; Wentzel 2002) through collective collaborative systems led to change processes in the professionals' existing practices and a visible reduction in challenging behaviors. Regular reflection on practice through observation and the documentation of children's learning experiences allows staff to face new challenges by being responsive to the needs and potentials of all children. Professionals' collective work can set the basis for constantly co-constructing, deconstructing and re-constructing educational practices through dialogue with children and by involving parents as equal partners in educational decision-making (European Commission 2014).

Domitrovich et al. (2012, p. 218) claim that: "Much of the research literature on organizational factors associated with the implementation of preventive interventions has been done in schools, but it is also relevant for early childhood education and care settings". A key to success in the BT capacity building proved to be the strong focus on implementation drivers in the change processes (e.g. Blasé et al. 2012; Domitrovich et al. 2012). Consequently, strengthening ECEC teachers' understanding of implementation processes is vital for their mastery of future innovations and should be emphasized in future ECEC research.

Acknowledgements I am grateful for the funding from the Office of the Governor of Vest-Agder, Norway that made this study possible. Docent Pål Roland at the National Centre for Learning Environment and Behavioural Research in Education, University of Stavanger, Norway has given highly constructive advice regarding this paper.

Open Access This article is distributed under the terms of the Creative Commons Attribution 4.0 International License (http://creativecommons.org/licenses/by/4.0/), which permits unrestricted use, distribution, and reproduction in any medium, provided you give appropriate credit to the original author(s) and the source, provide a link to the Creative Commons license, and indicate if changes were made.

\section{References}

Australian Children's Education and Care Quality Authority. (2017). National Quality Standard and Operational Requirements. Guide to the National Quality Standard. Sydney: Australian Children's Education and Care Quality Authority. Retrieved November 17, 2017, from http://files.acecqa.gov. au/files/NQF/Guide-to-the-NQF.pdf.

Bandura, A. (1986). Social foundation of thought and action: A social cognitive theory. Englewood Cliffs, NJ: Prentice Hall.

Bandura, A. (1997). Self-efficacy: The exercise of control. New York: Freeman. 
Bateson, G. (2000). Steps to an ecology of mind. Chicago: University of Chicago Press.

Baumrind, D. (1991). Parenting styles and adolescent development. In J. Brooks-Gunn, R. M. Lerner, \& A. C. Petersen (Eds.), The Encyclopedia of adolescence (pp. 746-758). New York: Garland.

Blasé, K. A., Van Dyke, M., Fixsen, D. L., \& Bailey, F. W. (2012). Implementation science: Key concepts, themes and evidence for practitioners in educational psychology. In B. Kelly \& D. F. Perkins (Eds.), Handbook of implementation science for psychology in education (pp. 13-34). Cambridge, United Kingdom: Cambridge University Press.

Bretherton, I., \& Parke, R. D. (1992). The origins of attachment theory: John Bowlby and Mary Ainsworth. Developmental Psychology, 28(5), 759-775. https://doi.org/10.1037/0012-1649.28.5. 759.

Bronfenbrenner, U. (1979). The ecology of human development: Experiments by nature and design. Cambridge: Harvard University Press.

Bronfenbrenner, U. (2005). Making human beings human: Bioecological perspectives on human development. Thousand Oaks: Sage.

Burke, W. W. (2008). Organization change. Theory and practice (2nd ed.). Thousand Oaks, CA: Sage Publications.

Cornell, D., \& Huang, F. (2016). Authoritative school climate and high school student risk behavior: A cross-sectional multi-level analysis of student self-reports. Journal of Youth and Adolescence, 45(11), 2246-2259.

Côté, S. M., Vaillancourt, T., LeBlanc, J. C., Nagin, D. S., \& Tremblay, R. E. (2006). The development of physical aggression from toddlerhood to pre-adolescence: A nation wide longitudinal study of Canadian children. Journal of Abnormal Child Psychology, 34(1), 68-82.

Crick, N. R., \& Dodge, K. A. (1994). A review and reformulation of social information-processing mechanisms in children's social adjustment. Psychological Bulletin, 115(1), 74-101.

Department for Education. (2017). Statutory framework for the early years foundation stage Setting the standards for learning, development and care for children from birth to five. England: Department for Education. Retrieved November 16, 2017, from https:/www.gov.uk/government/uploads/ system/uploads/attachment_data/file/596629/EYFS_STATUTORY_FRAMEWORK_2017.pdf.

Dodge, K. A., \& Coie, J. D. (1987). Social-information-processing factors in reactive and proactive aggression in children's peer groups. Journal of Personality and Social Psychology, 53, 1146-1158.

Dodge, K. A., Coie, J. D., \& Lynam, D. (2006). Aggression and antisocial behavior in youth. In N. Eisenberg, W. Damon, \& R. E. Lerner (Eds.), Handbook of child psychology: Social, emotional, and personality development (6th ed., Vol. 3, pp. 719-788). New Jersay: Wiley.

Domitrovich, C. E., Bradshaw, C. P., Poduska, J. M., Hoagwood, K., Buckley, J. A., Olin, S., et al. (2008). Maximizing the implementation quality of evidence-based preventive interventions in schools: A conceptual framework. Advances in School Mental Health Promotion, 1(3), 6-28. https:// doi.org/10.1080/1754730X.2008.9715730.

Domitrovich, C. E., Moore, J. E., \& Greenberg, M. T. (2012). Maximizing the effectiveness of socialemotional interventions for young children through high-quality implementation of evidence-based interventions. In B. Kelly \& D. F. Perkins (Eds.), Handbook of implementation science for psychology in education (pp. 207-229). New York: Cambridge University Press.

Downer, J. T., Kraft-Sayre, M. E., \& Pianta, R. C. (2009). Ongoing, web-mediated professional development focused on teacher-child interactions: Early childhood educators' usage rates and selfreported satisfaction. Early Education and Development, 20(2), 321-345. https://doi.org/10.1080/ 10409280802595425.

DuFour, R., Eaker, R., \& DuFour, R. (Eds.). (2005). On common ground: The power of professional learning communities. Bloomington, IN: National Educational Service.

Durlak, J. A., \& DuPre, E. P. (2008). Implementation matters: A review of research on the influence of implementation on program outcomes and the factors affecting implementation. American Journal of Community Psychology, 41(3-4), 327-350. https://doi.org/10.1007/s10464-008-9165-0.

Elliot, A. (2006). Early childhood education: Pathways to quality and equity for all children. Australian Education Review (No. 50). Melbourne: Australian Council for Educational Research.

Ertesvåg, S. K. (2011). Measuring authoritative teaching. Teaching and Teacher Education, 27(1), 51-61. https://doi.org/10.1016/j.tate.2010.07.002.

European Commission. (2014). Proposal for key principles of a Quality Framework for Early Childhood Education and Care: Report of the Working Group on Early Childhood Education and Care under the auspices of the European Commission. Brussel: Directorate-General for Education and Culture. 
Retrieved November 16, 2017, from http://ec.europa.eu/assets/eac/education/policy/strategicframework/archive/documents/ecec-quality-framework_en.pdf.

Fixsen, D. L., Naoom, S. F., Blasé, K. A., Friedman, R. M., \& Wallace, F. (2005). Implementation research: A synthesis of the litterature. Tampa, FL: University of South Florida.

Flaspohler, P., Duffy, J., Wandersman, A., Stillman, L., \& Maras, M. (2008). Unpacking prevention capacity: An intersection of research-to-practice models and community-centered models. American Journal of Community Psychology, 41(3-4), 182-196. https://doi.org/10.1007/s10464-008-9162-3.

Fullan, M. (2001). The new meaning of educational change (3rd ed.). New York: Teachers College Press. Fullan, M. (2007). The new meaning of educational change (4th ed.). New York: Teachers College Press.

Greenberg, M. T., Domitrovich, C. E., Graczyk, P. A., \& Zins, J. E. (2005). The study of implementation in school-based preventive interventions: Theory, research and practice. Washington, DC: U.S. Department of Health and Human Services, Substance Abuse and Mental Health Services Administration, Centre for Mental Health Services.

Hair, E., Halle, T., Terry-Humen, E., Lavelle, B., \& Calkins, J. (2006). Children's school readiness in the ECLS-K: Predictions to academic, health, and social outcomes in first grade. Early Childhood Research Quarterly, 21(4), 431-454.

Hall, G. E., \& Hord, S. M. (2015). Implementing change: Patterns, principles, and potholes (4th ed.). Boston, MA: Pearson Education.

Hamre, B. K., \& Pianta, R. C. (2005). Can instructional and emotional support in the first grade classroom make a difference for children at risk of school failure? Child Development, 76(5), 949-967.

Hargreaves, A., \& Fullan, M. (2012). Professional capital: Transforming teaching in every school. London: Routledge.

Hargreaves, A., \& Shirley, D. (2009). The fourth way: The inspiring future for educational change. Thousand Oaks, CA: Corwin Press.

Harms, T., Clifford, R. M., \& Cryer, D. (1998). Early childhood environment rating scale (Revised ed.). New York: Teacher College Press.

Hoge, M., Tondora, J., \& Marrelli, A. (2005). The fundamentals of workforce competency: implications for behavioral health. Administration and Policy in Mental Health and Mental Health Services Research, 32(5), 509-531. https://doi.org/10.1007/s10488-005-3263-1.

Hu, B. Y. (2015). Comparing cultural differences in two quality measures in Chinese kindergartens: The early childhood environment rating scale-revised and the kindergarten quality rating system. Compare: A Journal of Comparative and International Education, 45(1), 94-117.

Hu, B., \& Szente, J. (2009). Exploring the quality of early childhood education in China: Implications for teacher education. Journal of Early Childhood Teacher Education, 30(3), 247-262.

Joyce, B., \& Showers, B. (2002). Student achievement through staff development (3rd ed.). Alexandria: Association for Supervision \& Curriculum Development.

Kvale, S., \& Brinkmann, S. (2009). Interviews: Learning the craft of qualitative research interviewing (2nd ed.). Los Angeles, CA: Sage.

Laevers, F. (2005). The curriculum as means to raise the quality of early childhood education. Implications for policy. European Early Childhood Education Research Journal, 13(1), 17-29.

LaParo, K., Hamre, B., \& Pianta, R. (2012). Classroom Assessment Scoring System (CLASS) Manual, Toddler. Baltimore, MD: Paul H. Brookes.

Legislative Budget Board. (2007). Early childhood care and education programs in Texas. Policy Report. Retrieved November 18, 2017, from http://www.lbb.state.tx.us/Documents/Publications/Policy_ Report/Early\%20Childhood\%20Care\%20and\%20Education\%20Programs\%20in\%20Texas.pdf.

Leithwood, K. A., \& Beatty, B. (2008). Leading with teacher emotions in mind. Thousand Oaks, CA: Corwin Press.

Mead, G. H., \& Morris, C. W. (1934). Mind, self, and society: From the standpoint of a social behaviorist (Vol. 1). Chicago: University of Chicago Press.

Ministry of Education and Research. (2015). OECD: Thematic review of early childhood education and care policy in Norway. Background Report. Oslo: Ministry of Education and Research. Retrieved November 17, 2017, from https://www.regjeringen.no/contentassets/ 6372d4f3c219436e990a5b980447192e/oecd_rapport_2015_kd_web.pdf.

Ministry of Education and Research. (2017). Framework plan for the ECEC institution's content and tasks. Oslo: Ministry of Education and Research. Retrieved November 14, 2017, from https://www. udir.no/globalassets/filer/barnehage/rammeplan/framework-plan-for-kindergartens2-2017.pdf. 
OECD. (2015). Early Childhood Education and Care Policy Review Norway. OECD. Retrieved November 14, 2017, from https://www.regjeringen.no/contentassets/6372d4f3c219436e990a5b980 447192e/oecd_norway_ecec_review_final_web.pdf.

OECD. (2016). Starting strong IV: Monitoring quality in early childhood education and care. OECD. Retrieved November 18, 2017, from https://www.oecd.org/edu/school/ECECDCN-Chile.pdf.

Patton, M. Q. (2002). Qualitative research \& evaluation methods (3rd ed.). Thousand Oaks, CA: Sage Publications.

Pellerin, L. A. (2005). Applying Baumrind's parenting typology to high schools: Towards a middle-range theory of authoritative socialization. Social Science Research, 34, 283-303.

Pianta, R. C. (1999). Enhancing relationships between children and teachers. Washington, DC: American Psychological Assosiation.

Pianta, R., Howes, C., Burchinal, M., Bryant, D., Clifford, R., Early, D., et al. (2005). Features of prekindergarten programs, classrooms, and teachers: Do they predict observed classroom quality and child-teacher interactions? Applied Developmental Science, 9(3), 144-159.

Pramling, I., Sheridan, S., \& Williams, P. (2006). Five preschool curricula-Comparative perspective. International Journal of Early Childhood, 38(1), 11-30.

Prince Edward Island Department of Education and Early Childhood Development. (2008). Kindergarten Integrated Curriculum Document. Prince Edward Island Department of Education and Early Childhood Development. Retrieved November 18, 2017, from http://www.gov.pe.ca/photos/ original/k_doc.pdf.

Qi, X., \& Melhuish, E. C. (2016). Early childhood education and care in China: History, current trends and challenges. Early Years: An International Journal of Research and Development, 37(3), $268-284$.

Report no. 16 to the Storting. (White Paper). (2006-2007). And none was left behind: Early intervention for lifelong learning. Oslo: Ministry of Education and Research. Retrieved November 14, 2017, from https://www.regjeringen.no/en/dokumenter/report-no.-16-to-the-storting-2006-2007/id441395/

Report no. 18 to the Storting. (White Paper). (2010-2011). Learning and community: Early intervention and positive learning environments for children, youth and adults with special needs. Oslo: Ministry of Education and Research. Retrieved November 14, 2017, from https://www.regjeringen.no/no/ dokumenter/meld-st-18-20102011/id639487/.

Report no. 19 to the Storting. (White Paper). (2015-2016). Time for playing and learning: Better content in the ECEC institution. Oslo: Ministry of Education and Research. Retrieved November 14, 2017, from, https://www.regjeringen.no/no/dokumenter/meld.-st.-19-20152016/id2479078/.

Richards, L. (2002). Using NVivo in qualitative research. Melbourne: QSR International.

Senge, P. M. (2006). The fifth discipline: The art and practice of the learning organization. New York: Currency/Doubleday.

Siraj-Blatchford, I., Sylva, K., Muttock, S., Gilden, R., \& Bell, D. (2002). Researching effective pedagogy in the early years. Research Report (No. 356). London: Department for Education and Skills.

Stoll, L., Bolam, R., McMahon, A., Wallace, M., \& Thomas, S. (2006). Professional learning communities: A review of the literature. Journal of Educational Change, 7(4), 221-258. https://doi. org/10.1007/s10833-006-0001-8.

Stoll, L., \& Seashore, L. K. (2007). Professional learning communities: Divergence, depth and dilemmas. New York: McGraw-Hill Education.

The National Committee for Research Ethics in the Social Sciences and the Humanities (NESH). (2006). Guidelines for research ethics in the social sciences, law and the humanities. Oslo: The National Committee for Research Ethics in the Social Sciences and the Humanities.

The World Bank. (2013). What matters most for early childhood development: A framework paper. Systems Approach for Better Education Results (Saber) Working Paper Series, No. 5. Washington, DC: The World Bank. Retrieved November 17, 2017, from http://wbgfiles.worldbank.org/ documents/hdn/ed/saber/supporting_doc/Background/ECD/Framework_SABER-ECD.pdf.

Tremblay, R. E. (2010). Developmental origins of disruptive behaviour problems: the "original sin" hypothesis, epigenetics and their consequensis for prevention. Journal of Child Psychology and Psychiatry, 51(4), 341-367.

Umayahara, M. (2006). Background paper prepared for the Education for All Global Monitoring Report 2007 Strong foundations: early childhood care and education Early Childhood Education Policies in Chile: From pre-Jomtien to post-Dakar. UNESCO. Retrieved November 18, 2017, from http:// unesdoc.unesco.org/images/0014/001474/147494e.pdf. 
UNESCO. (2010). Status and development of the preschool education system in the Russian Federation. Early childhood care and education country report. Ministry of Education and Science of the Russian Federation 2010. Country report. Retrieved November 18, 2017, from http://unesdoc. unesco.org/images/0018/001893/189374e.pdf.

UNESCO. (2015). Incheon Declaration and Framework for Action for the implementation of Sustainable Development Goal 4. Ensure inclusive and equitable quality education and promote lifelong learning opportunities for all. Paris: UNESCO. Retrieved November 14, 2017, from http://unesdoc. unesco.org/images/0024/002456/245656E.pdf.

UNICEF. (1989). The United Nations Convention on the Rights of the Child. London: UNICEF. Retrieved November 17, 2017, from http://www.unicef.org.uk/wp-content/uploads/2010/05/ UNCRC_united_nations_convention_on_the_rights_of_the_child.pdf.

Walker, J. M. T. (2008). Looking at teacher practices through the lens of parenting style. Journal of Experimental Education, 76(2), 218-240. https://doi.org/10.3200/JEXE.76.2.218-240.

Wandersman, A., Coyne, S. M., Duffy, J. L., Clary, E. G., Forbush, J., \& Weinberger, S. G. (2006). Community organizing and advocacy: Increasing the quality and quantity of mentoring programs. Journal of Community Psychology, 34(6), 781-799. https://doi.org/10.1002/jcop.20129.

Wang, J., Elicker, J., McMullen, M., \& Mao, S. (2008). Chinese and American preschool teachers' beliefs about early childhood curriculum. Early Child Development and Care, 178(3), 227-249.

Wentzel, K. R. (2002). Are effective teachers like good parents? Teaching styles and student adjustment in early adolescence. Child Development, 73(1), 287-301. https://doi.org/10.1111/1467-8624.00406. 